\title{
Deviations of Spot Colorimetric Values on Multi-layered Flexible Packaging during the Graphic Reproduction and Sterilisation Process
}

\author{
Renata TOMERLIN, Mario TOMIŠA, Damir VUSIĆ
}

\begin{abstract}
The main goal of the packaging production process is to ensure quality reproduction of color and design in general, so that the quality of the final product meets all requirements necessary for food packaging. Colors are one of the key components of brand recognition and the creation of an emotional connection with consumers which is the basis of this paper. Aside from conventional packaging materials, more and more food products are marketed in multi-layered flexible packaging. The samples that form the basis of this paper are printed on polyester film (PET) using a rotogravure printing technique. During the finishing phase, the PET layer are laminated on layer of aluminium (Al), oriented polyamide (OPA) and polypropylene (PP) and then, after cross linking, they are die-cut and formed into stand-up pouch. During the graphic reproduction, graphic preparation, printing and finishing processes, colors show various deviations. The main goal of this paper is to examine the influence of the individual phases of these processes on the manner in which red spot color reacts to and determines deviations $\left(\Delta E^{*}\right)$ in relation to a defined formula and color standard. Color deviations may also occur during the finishing and sterilisation process. In order that colorimetric spot colors may be monitored, it is necessary to define a formula and standard and conduct measuring after each stage of the graphical process in the $\mathrm{CIE} \mathrm{L}^{*} \mathrm{a}^{*} \mathrm{~b}^{*}$ color space. Based on the measured results, guidelines and recommendations were produced for the correction and control of color reproduction throughout the defined process which aim to reduce deviation to an acceptable level.
\end{abstract}

Keywords: CIE L*a* $\mathrm{b}^{*}$; deviations; packaging; polymeric material; spot color; sterilisation

\section{INTRODUCTION}

Wrapping a product in packaging includes production and design processes. Traditionally, the primary function of packaging was to hold the product and protect it from external elements. More recently numerous factors have impacted and made packaging an important marketing tool. Increased competition and crowded shelves in retail chains suggest that packaging itself is a major factor in a purchasing decision [1].

The advantage a particular product retains in relation to its competition lies in its ability to retain a consumer's attention for a short time at the point of sale while a purchasing decision is made. The most dominant stimulus throughout this process is visual, and therefore packaging becomes a key element in making a purchasing decision [2].

As an integral part of any design is the color that creates an emotional connection between the consumer and the brand, increasing recognition on the shelf and creating brand loyalty.

A social community is overcrowded by packaging, as is necessary for all sold manufactured goods which need to be wrapped, promoted and protected during handling and storage on their path to the end user: the consumer. Without the use of packaging, handling materials would be an untidy, ineffective and costly affair, and modern retail would be impossible. Packaging for food products is an essential component of today's modern food industry [3].

Table 1 Properties of monomers that are transferred to the production of multilayer packaging [4]

\begin{tabular}{|l|l|}
\hline \multicolumn{1}{|c|}{ Material } & \multicolumn{1}{|c|}{ Properties } \\
\hline Paper & Strong, rigid, opaque, printable and can be metallised. \\
\hline Aluminium Foil & $\begin{array}{l}\text { Negligible water vapour, gas and odour permeability, resistant to grease, opaque, reflective and retains a shape when } \\
\text { bent. }\end{array}$ \\
\hline Cellulose Film (lacquer) & $\begin{array}{l}\text { Can be machine-processed, strong, transparent, glossy, oil and grease-resistant, can be thermally welded shut and is } \\
\text { water vapour, gas and odour-permeable, depending on the type of lacquer (coats) applied. }\end{array}$ \\
\hline PE and Ethylene Co-polymers & $\begin{array}{l}\text { Durable, can be thermally welded shut, low water vapour permeability, good chemical resistance, good low- } \\
\text { temperature resistance and can be metallised. Ethylene co-polymers improve strength and resistance at low } \\
\text { temperatures and decrease the thermal welding temperature. }\end{array}$ \\
\hline PE-LLD and Ionometers & Improved resilience and can be hot welded intermittently. \\
\hline PP and PP Co-polymers & $\begin{array}{l}\text { Very low water vapour permeability, thermal seam resistance to sterilisation temperatures, mechanical strength at low } \\
\text { temperatures depending on the proportion and type of co-polymer. }\end{array}$ \\
\hline OPP & $\begin{array}{l}\text { Highly transparent and glossy, a very effective barrier to water vapour, good mechanical strength and co-extruded films } \\
\text { for thermostability. Films coated with PVDC films have good protecting properties against gases and odours and are } \\
\text { thermostable. }\end{array}$ \\
\hline Metallised OPP & Improved barrier properties to gases, moisture and UV and light rays \\
\hline Polyester Film (PET) & $\begin{array}{l}\text { Transparent and glossy, durable, thermostable and a good barrier for water vapour. Coated films have good barrier } \\
\text { properties for moisture, gases and odours. }\end{array}$ \\
\hline
\end{tabular}

Nowadays polymeric materials, which are generally known as plastic materials, are used more and more in conjunction with conventional packaging materials such as glass, metal, paper and cardboard. Changes in society and general lifestyles have led to a number of changes in food production and processing and in turn to the expansion and development of many opportunities in the packaging material industry. Plastic materials are responsible for a number of positive changes related to the food packaging. Plastic production is one of the cheapest production processes in the production packaging material sector: they are easy to handle and transport, attractive, they can be finally decorated in a variety of ways and meet the requirements for protecting food from external elements. The disadvantage of plastic packaging is the inadequate disposal and lack of waste product treatment. 
Polymeric materials can be used as mono-materials for packaging food products, but it is common practise to combine multiple layers of polymeric materials $[5,6]$. In most instances, self-contained polymeric materials are insufficient to ensure all the requirements that packaging has to meet. This group of materials do not belong to the group of inert packaging materials, for example, glass, and it is necessary to utilise different combinations of packaging materials in order to increase the functional characteristics of packaging (Tab. 1). In order to ensure the food product's required shelf-life and prevent damaging of the product caused by handling, various polymeric materials are combined with each other and with layers of metallised foils, most often aluminium. Combinations with paper are also possible. The resulting composite, multilayered and flexible materials are known as MMML (Multi Material Multi Layer).

Packaging can be defined as a combination of art and science: it is the material and equipment, the protection and promotion, the legislation and logistics and the production and handling of materials [7].

Packaging production is an important industry in many national economies, and the Smithers Pira Organisation predicts that the global packaging market will grow. Total value in the global packaging industry in 2018 will reach $\$ 876$ billion, with steady growth pushing this value past $\$ 1$ trillion in 2023. By 2028 an additional $\$ 150$ billion will have been added to this market [8].

A composite multilayer flexible material has been used to make samples for this paper because, in addition to the polymer, it contains an aluminium layer which provides an adequate barrier and is strong enough to contain food products and withstand the processes they are subject to. This composition of the packaging material is the following (Fig. 1): PET 12 $\mu / \mathrm{Al} 9 \mu / \mathrm{OPA} 15 \mu / \mathrm{PP} 75 \mu$.

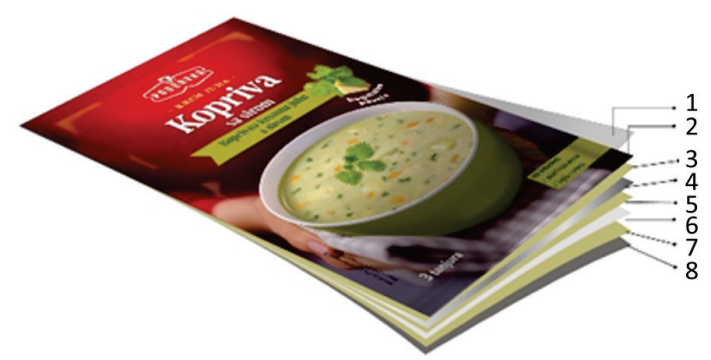

Figure 1 Stand-up pouch Material Layers: 1 - Polyester (PET), 2 - Printing Ink 3 - Laminate adhesive, 4 - Aluminium (Al), 5 - Laminate adhesive, 6 - Oriented polyamide (OPA), 7 - Laminate adhesive, 8 - Polypropylene (PP)

The stated composition of the packaging material is suitable for sterilisation treatment, which means that both the finished food product and packaging will be exposed to an aggressive temperature regime.

\section{THE IMPORTANCE OF PACKAGING AND VISUAL PERCEPTION}

The goal of this paper is to define the spot red color deviation in the CIE $\mathrm{L}^{*} \mathrm{a}^{*} \mathrm{~b}^{*}$ color space, which is applied to packaging design in order to detect the phase in the process which the greatest deviations occur in relation to the proscribed standard and the defined color formula for Podravka Red spot color. Standard values for Podravka Red spot color were prescribed in Podravka Packaging and
Design Department. Today consumers are exposed to a variety off-the-shelf products, and they choose and buy them for a variety of reasons. One of the instruments used to attract and retain consumer attention and ultimately influence their purchasing decision is the visual aspect, i.e. the packaging design in its entirety and primarily through color. The majority of retail chains own-brand products use the same or similar color shades as the ones subject to a protected trademark. There are a number of examples on the market imitating Coca Cola, Nivea, Vegeta, etc. The goal is to protect the shade of the color and to always keep it within the defined tolerance limits during the production of packaging and other printed materials to avoid any possibility of misleading consumers once a product is on the shelf.

Consumers tend to associate color with a product's taste. A previous study, which has been carried out by Rebollar, Lidón, Serrano, Martín, and Fernández conducted with 390 respondents rating 30 attributes on 9 different chewing gum designs, showed that the decision to purchase was closely related to the color of the packaging [9]. Respondents perceived packaging in warm colors with fruity, sour or sweet flavours, while the packaging in cold colors were associated with menthol and spice flavours. Respondents also thought that cold-colored packaging had a more intensive and longer-lasting flavour. An analysis of the responses found that warm colors were associated with fun, dynamism, sensuality and rebellion, all of which were linked together by the younger population that was part of the survey. On the other hand, grey was associated with elegance and mysteriousness. A color-impact analysis of willingness to buy showed consumers were most likely to choose packaging in warm colors, then in cold colors and finally in shades of grey.

When choosing and defining a particular brand's colors, it is important to clearly define a brand's attributes, who the product is for, what it is like and what emotions are to be elicited from consumers, users and the like. A clear and precise brief will help a designer produce the most appropriate solution. The choice of color highlights the brand's character and sends a strong message. Aside from trends and other parameters defined in the brief, the choice of color must respect the cultural meanings of such colors which differ from country to country. Designers should be extremely careful when creating global brands as not a single color has identical meaning in all countries, and accordingly the context is therefore important. Color is linked on an emotional level with a brand, and clearly it is important that such emotions are positive. While designers in the past have been limited by the number of colors and shades that they could use, the spectrum used today is wider and more susceptible to trends. The importance and role of colors have been recognised and trends are imposed through the media leading to new shades being created every year. Pantone color system is the most well known professional system for colors. It is universally accepted within the graphics industry and makes it easier for designers, marketing managers and printers to standardise quality. It also dictate trends over the past few years in other industries, such as fashion, cosmetics, furniture and decorative objects. Colors have become a powerful tool for communicating messages and expressing the character of companies, brands and general consumer goods. Podravka 
has selected and defined a red color for its branded packaging and has been using it since it began production in the 1950s. The current red color used to express Podravka's corporate visual identity was defined in 1994. The subject of this paper is the design of Podravka Cream Soup in its dominant red color. When manufacturing packaging for Podravka products, it is important that the frames and boundaries for defined tolerance areas for color deviation are observed, regardless of the substrate and base upon which the printing takes place and the supplier producing the packaging. The allowed tolerance for Podravka's red color is $\Delta E \leq 2$. In order to meet these requirements, it is very often necessary to redefine the color formula after measuring of CIE $L * a * b *$ values. Colors on different packaging materials, printed by different suppliers and with different printing techniques do not behave in an identical manner.

The environment in which the color is presented is also important. Different combinations provide different effects. Yellow on black will appear aggressive while on a white background it looks darker with a fine warming effect. A red color will look dark and pronounced on a white square, on a black background it will radiate heat, while blue on white will appear dark and deep, and on white it will appear brighter in comparison with its combination with yellow. On a black square, blue will have a brilliant character with a deep luminescence of shade [10].

During the design process a designer should bear in mind the rules for combining colors and the effects that will be achieved by such combinations and the fact that transgressing the frame will not necessarily not result in a good and striking design. Another limiting factor for designers is the possibility of simple applications in all forms of communication, from print media and packaging to television and the Internet. Clear and clean combinations, using the smallest number of colors, are preferred, as this prevents additional printing, reproduction and standardisation costs. In order that defined and branded colors can be properly applied to all communications channels within tolerance areas, rules should be clearly articulated and defined and all procedural participants should be acquainted with them [11].

\section{RESEARCH METHODOLOGY}

This Chapter described the methodology used in this paper and the impact of specific graphic-technological processes on the deviation of the Podravka Red spot color. In this paper the results of CIE $\mathrm{L}^{*} \mathrm{a} \mathrm{b}^{*}$ measurements of color and its deviation are compared to the measured and defined standards and the tolerance area with the goal of detecting the process stage in which the greatest deviation from the tolerance areas is found that affects consumer perception. The graphic design process of packaging production is divided into four phases: graphic design, printing preparation, printing and finishing. Aside from these phases, the finished packaging products referred to in this paper were also exposed to treatment of the completed product, i.e. sterilisation, which meant exposure to an aggressive temperature regime over a pre-determined period of time.

\subsection{Design, Graphic Preparation and Creation of Printing Forms}

Packaging design starts with a good, clear and detailed brief for both the agency and the designer. To create a welldefined brief the specific parameters that form an integral part of it have to be known. Actual realisation of the standup pouch, from the inception of the idea to the engraving of printing forms, took place in the order listed below.

The Company Aluflexpack Novi is the only Croatian producer of stand-up pouches made from multi-layer flexible packaging that utilise a print medium that can be sterilised or exposed to other types of food processing. Podravka wishes to introduce this type of finished liquid, sterilised product into their range. Given that Aluflexpack Novi is their packaging production partner, an initial inquiry and consultations were held with them.

The research component of the work began with the application of the design to the technical drawings of standup pouch made from multi-layer flexible packaging with a $500 \mathrm{ml}$ capacity measuring 140x240 $\mathrm{mm}$. This type and packaging format is part of Aluflexpack Novi's standard packaging process and formatted parts and possible production methods were available for this specified format. Podravka has sought a suitable solution from the existing portfolio and the range of tools available to the packaging manufacturer, and amended their requirements to a stand-up pouch that was already in production with defined parameters in order to avoid additional costs. A color measurement atlas was applied to the pouch background.

Adobe Illustrator CC software was used for graphic design preparation. Colour separation was made in Esko, ArtPro Version 16.0.0 software by company Anilox. Input separation for sample printing was performed in six colours (blue-green, purple, yellow, black, Podravka Red and white). A trial print was made on an Epson Stylus Pro WT7900 printer, using ink jet printer technology and a Micro Piezo TFP print head. The Printer uses GMG RIP and GMG FlexoProof Ver.5.8.1.312 Color Management Software. Following separation, a test print was made using digital technology (a GMG proof). Podravka then received a PDF file with final separation and the GMG imprint, and once again all the parameters were checked, signed-off and returned to the packaging manufacturer as confirmation that they could move to the next stage of the process. The most important element here is that, prior to the roller engraving stage, in which sizeable financial repercussions can result from a mistake, all must be verified and signed. After confirmation of the graphic preparation stage the following stage involves the creation of printing forms, or in this instance the engraving of rollers.

The files were engraved with the Collage Application, which installed and assigned the following parameters:

- Lineature, $(70 \mathrm{~L} / \mathrm{cm}-101 \mathrm{~L} / \mathrm{cm}$, depends on color)

- Specific separation angles, $\left(33^{\circ}-60^{\circ}\right.$, depends on color)

- Tool angle, $\left(110^{\circ}-130^{\circ}\right.$, depends on color $)$

- Reproduction curve.

Prepared rollers were engraved on an electronic engraving machine with files prepared in Collage. The 
engraving was performed by Ohio Gravure Tec. Inc. USA, Gravostar Spectrum Engraving Machine, with tools, lineature and gamma curves characteristic of the selected print media and Aluflexpack Novi's print shop, where printing was to be performed. The print rollers were finally processed with a hard chrome plating, where a protective layer of chromium, several micro millimetres thick, was applied, thus ensuring the rollers were sufficiently durable to withstand printing on the printing machines. The chrome roller then passed through the final quality control stage where the test print, including the original printing inks defined by the end-user and simulated parameters of the printing machine was made and the test sample, was checked. A test print with the engraved rollers was performed on a press and this process was mostly carried out manually. This print showed any of the rollers' defects and indicated any possible additional finishing. Test printing proof was performed on the test print machine, Rotogravure Proofing Press, produced by JM Heaford UK, Model HA 3,500 $\times 1,800$ (Fixed Drum/Hydraulic Rotation), using the engraved rollers for the final control phase before print.

\subsection{Printing and Finishing}

The patterns that are the subject of this paper have been printed using a rotogravure printing technique. Rotogravure printing is a direct, intaglio printing technique. The print face is hollowed out in its printed form and the blank spaces are foremost [12]. Printing ink is applied on the entire print form during printing and later, a doctor blade removes printing ink from the blank spaces (Fig. 2). By pressing the printing form onto the substrate, the printing ink is transferred to the substrate [13]. Printing surface of PET foil should be treated to be suitable for printing, which has a significant influence on surface tension and enable the ink to connect with the printing substrate [14].

This printing technique allows reproduction of very small details, small font-sized text, excellent photographs and product views. The usual perception of copper-plate engraving within the printing industry is that it is used in printing top class brand packaging which require highquality. Quality remains the main feature of printing technology, but in recent years the producers of printing forms, i.e. engraving companies have sought to reduce costs and automate the process. New, fast engraving heads are fully robotically automated, replacing human labour and leading to significantly shorter delivery times, often no longer than a few days [15].

Aside from high prices of the printing forms, copperplate engraving is also known for evaporation dye finishing. Most printing that utilises this technique involves dyes based on organic solvents. The vapours from organic solvents are harmful to human health and highly flammable. For these reasons, plants and facilities where copper-plate engraving machines are used require special construction and safety [13]. Companies operating within the EU are subject to stringent legislation and must be equipped with special types of air purification and solvent recovery.

Aluflexpack Novi print shop in Umag printed design samples on a Schiavi Pulsar Printing Machine, 10 group,
$1,240 \mathrm{~mm}$ wide with a maximum speed of $350 \mathrm{~m} / \mathrm{min}$, utilising a copper-plate engraving technique on transparent, $12 \mu$ thick polyester (PET). Aluflexpack Novi utilises a cutting edge solvent recovery plant and has been awarded BRC (the British Retail Consortium) and ISO (the International Organisation for Standardisation) production certification.

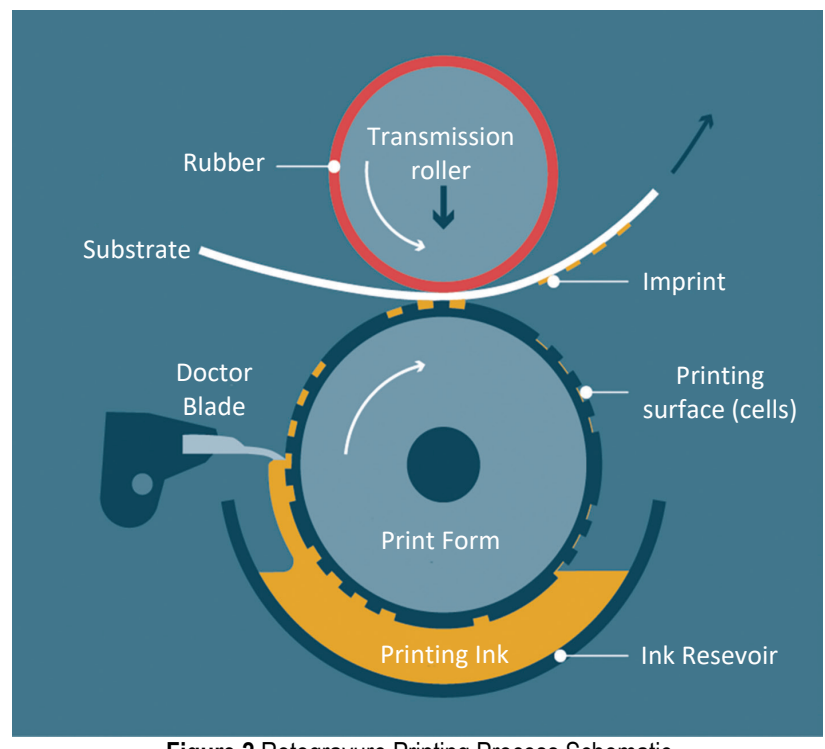

Figure 2 Rotogravure Printing Process Schematic

Special Siegwerk printing inks (thermal-resistant colors) was used for printing. Resistances of this ink series by using completely resistant pigments according to ISO 2836. Inks are suitable for application on untreated PET, electrically or chemically treated PET, PVdC-coated PET, SiOx-coated PET, AlOx-coated PET (only with suitable primer) and electrically treated OPA. This ink series is intended for printing primary food packaging on the nonfood contact side of food packaging. Density of ink is 0,99 $\mathrm{g} / \mathrm{cm}^{3}\left(20^{\circ} \mathrm{C}\right)$, and kinematic viscosity $21 \mathrm{~mm} 2 / \mathrm{s}\left(40^{\circ} \mathrm{C}\right)$. The printed samples were measured for values of Podravka Red and compared with the set standard values and predefined color formula. After the printing phase was completed, the laminating process was performed on the Rotomec machine Rotoconvert with 3 unwinders (a triplex in a single pass) $1,230 \mathrm{~mm}$ wide with a maximum speed of $300 \mathrm{~m} / \mathrm{min}$. A Henkel agent and a catalysts were used for lamination. A flexible stand-up pouch consists of four different materials: PET, Al, OPA and PP. Following crosslinking of materials and solvent evaporation, measurements were made of the printed and laminated samples. The Totani BH-60DLLS machine was used to produce the stand-up pouches, operating at a maximum speed of $1,000 \mathrm{pouch} / \mathrm{min}$.

\subsection{Sterilisation}

Packaging is an integral part of a product on the shelf, and the goal of this paper is to define its behaviour throughout all phases of the graphic process and processing of the finished product. In the processing phases of the finished product, food products and packaging are processed together and exposed to very aggressive temperatures, which in turn has an extensive influence of the packaging and the behaviour of properties. 
Sterilisation of finished, packaged food is performed in autoclaves, pressurised devices which heat the finished products.

The sterilisation process is divided into 3 main stages: - In the first stage a medium (water or steam) is heated and the product's temperature is increased from ambient to the desired and default sterilisation temperature,

- In the second stage the products are exposed to the afore-mentioned temperature for a pre-determined period of time, and

- In the third stage the product is cooled by the introduction of water into the autoclaves [16].

This paper simulated this process with water because the finished product and its characteristics are not the subject of this paper. Formed samples, pouches, were filled with water and manually sealed on the top at the Podravka Packaging Development Laboratory.

Samples were filled with water and processed in two sterilisation regimes. The sterilisation regimes applied were:

- Air/steam, and

- Spray.

This procedure was carried out in an autoclave for batch sterilisation produced by Essai Lagarde, Autoclave Type RP315 N^A_1 S: AX00189836. Samples were processed at a temperature of $128{ }^{\circ} \mathrm{C}$ for 30 minutes under 2.6 bar pressure.

\section{MEASUREMENT RESULTS}

Evaluation of measured samples within this paper was performed on 25 samples, for the printing, lamination and sterilisation stages. The total quantity of produced samples was 1000 pieces. Samples for this paper were selected when the quality of the reproduction on the printing machine was set. Values were measured after printing, samples were marked and values were measured on the same samples after the lamination phase and sterilization process. Changes in the colorimetric values of samples were monitored during the printing stage, which was defined on a measuring device using the standard formula for CIE L*a*b* colorimetric values for Podravka Red spot colors. The color was measured with a Hunter Associates Lab. Inc. Device, Type: ColorQuest XE, in Aluflexpack Novi's print shop. The device was calibrated to accord with ISO/IEC 17025:2005 and BS EN ISO 9001:2000 Standards. The samples were measured after each process stage, starting with printing, and the influence of each individual phase on CIE $\mathrm{L}^{*} \mathrm{a}^{*} \mathrm{~b}^{*}$ components in the color space was precisely determined. For calculation of colorimetric deviation values was used the $\Delta E_{\mathrm{CMC}}$ formula. It was also defined in which process stage and under which processing regimes the largest deviation occurred and in which CIE $\mathrm{L}^{*} \mathrm{a}^{*} \mathrm{~b}^{*}$ color space values they were the most prominent. Following measurement, the statistical method of the arithmetic mean was used to define the average deviations for each phase. Parallel curves were also shown after each measurement stage along with deviation values compared to the measured standard.
The measurement was made with three standard light sources: D65. $/ 10^{\circ}$, A.../10 $/ 0^{\circ}$ and F11./10 . Aluflexpack Novi's print shop had previously recorded the CIE L*a* ${ }^{*}{ }^{*}$ color values that are the subject of this Research and the defined formula. The color formula which is the subject of this Research was, to a lesser extent, modified in its composition and did not use the original values.

The following standard values were defined for Podravka Red:

- Standard values for Podravka Red under light source D65./10 : L* $53.40 \quad a^{*} 52.74 \quad b^{*} 28.23$

- $\quad$ Standard values for Podravka Red under light source
A.../10 $:$ L $^{*} 61.13 \quad \mathrm{a}^{*} 52.81 \quad \mathrm{~b}^{*} 42.01$

- Standard values for Podravka Red under light source F11./10 : $\mathrm{L}^{*} 58.41 \quad \mathrm{a}^{*} 53.36 \quad \mathrm{~b}^{*} 36.56$

Following measurement and evaluation of all samples, comparisons of deviations for each process phase were made. The largest deviation of the Podravka Red color occurred after the lamination stage. Measurement results were analysed by the statistical method and expressed as an arithmetic mean of the results from the 25 stand-up pouch samples.

The term used to denote difference within the CIELAB color space is $\Delta E_{a b}^{*}$, a value obtained using the following formula:

$\Delta E_{a b}^{*}=\left(\Delta L^{* 2}+\Delta a^{* 2}+\Delta b^{* 2}\right)^{\frac{1}{2}}$

The CIE Lab was taken over by the CIE Commission in 1976 and represents a three-dimensional color model rendering whose calculation uses square roots.

Color Measurement Committee (CMC) and Association Dyers and Colourists from England developed a formula for showing the relationship of the color difference based on the CIE Lab formulas in 1963 [18]. It is standardized in the United States and England and recommended by the International Standards Organization (ISO). The formula was finally completed and published in 1984 and reads:

$\Delta E_{\mathrm{CMC}}=\sqrt{\left(\frac{\Delta L}{l S_{L}}\right)^{2}+\left(\frac{\Delta \mathrm{C}}{c S_{C}}\right)^{2}+\left(\frac{\Delta H}{S_{H}}\right)^{2}}$

Evaluation of differences in colorimetric values of measured colors, from the viewpoint of a standard observer, can be determined according to the following criteria (Tab. 2). Simple assessment of color deviation can be performed on the basis of colorimetric difference by applying the following criteria [19]:

Table 2 Colorimetric Difference Evaluation Criteria for Measured Colors

\begin{tabular}{|l|l|}
\hline$\Delta E^{*}<1$ & A deviation that cannot be noticed \\
\hline$\Delta E^{*}=(1-2)$ & $\begin{array}{l}\text { A very small deviation, noticeable only to the } \\
\text { experienced observer }\end{array}$ \\
\hline$\Delta E^{*}=(2-3.5)$ & $\begin{array}{l}\text { A medium deviation, noticeable to the } \\
\text { inexperienced observer }\end{array}$ \\
\hline$\Delta E^{*}=(3.5-5)$ & Difference \\
\hline$\Delta E^{*}>6$ & Significant difference \\
\hline
\end{tabular}


Average Value for Podravka Red Color Deviation:

1. Podravka Red print - deviation from the standard

- D65./10 $-\mathrm{CMC} 2: 1=0.38$

- $\quad$ A... $/ 10^{\circ}-\mathrm{CMC} 2: 1=0.41$

- $\quad \mathrm{F} 11 . / 10^{\circ}-\mathrm{CMC} 2: 1=0.39$

2. Podravka Red lamination - deviation from the standard

- D65. $/ 10^{\circ}-\mathrm{CMC} 2: 1=3.80$

- $\quad$ A... $/ 10^{\circ}-\mathrm{CMC} 2: 1=4.20$

- $\mathrm{F} 11 . / 10^{\circ}-\mathrm{CMC} 2: 1=4.10$

3. Podravka Red air/steam sterilisation - deviation from the standard

- $\quad \mathrm{D} 65 . / 10^{\circ}-\mathrm{CMC} 2: 1=3.10$

- $\mathrm{A} . . . / 10^{\circ}-\mathrm{CMC} 2: 1=3.45$

- $\quad \mathrm{F} 11 . / 10^{\circ}-\mathrm{CMC} 2: 1=3.37$

4. Podravka Red spray sterilisation - deviation from the standard

- $\quad$ D65. $/ 10^{\circ}-\mathrm{CMC} 2: 1=3.08$

- $\quad$ A.../10 $/ 10^{\circ}-\mathrm{CMC} 2: 1=3.39$

- $\quad \mathrm{F} 11 . / 10^{\circ}-\mathrm{CMC} 2: 1=3.33$

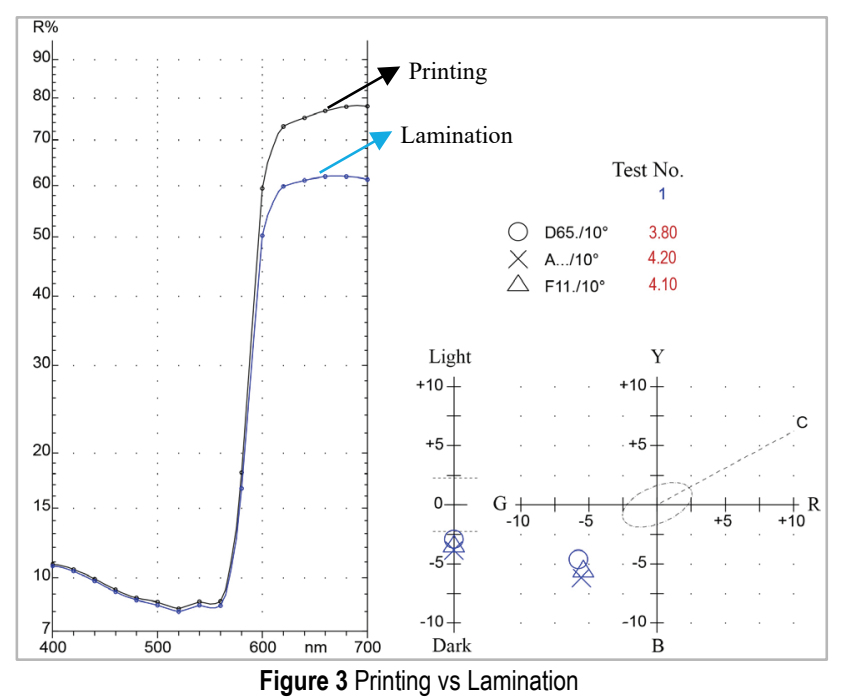

Presented Figs. 3 and 4 show the spectral curves of measured Podravka Red spot color regarding to the performed stage of the process. The right part of the picture shows L diagram with two wavelenght of color in two phases and ab diagram shows the color difference between the two phases. Deviation after printing is within tolerance limits and for light source D65./10 ${ }^{\circ}$ it amounts to CMC2:1 $=0.38$. After lamination the situation changes rapidly, the color exceeds the defined tolerance ranges and deviation for D65. $/ 10^{\circ}$ amounts to $\mathrm{CMC} 2: 1=3.80$ under the same conditions (Fig. 3). Unexpectedly after air/steam and spray sterilisation, Podravka Red demonstrates improvement by reduced deviation with the mean value of the measured samples amounting to $\mathrm{D} 65 . / 10^{\circ} \mathrm{CMC} 2: 1=3.10$ (air/steam) and D65. $/ 10^{\circ} \mathrm{CMC} 2: 1=3.08$ (Fig. 4). With lamination the Podravka Red color darkens and bleeds into the greenblue. It is evident that the sterilisation process effects the brightness of the polymer and that the brightness of Podravka Red partially returns to the initial values, which is evident by comparing the curve with lamination.

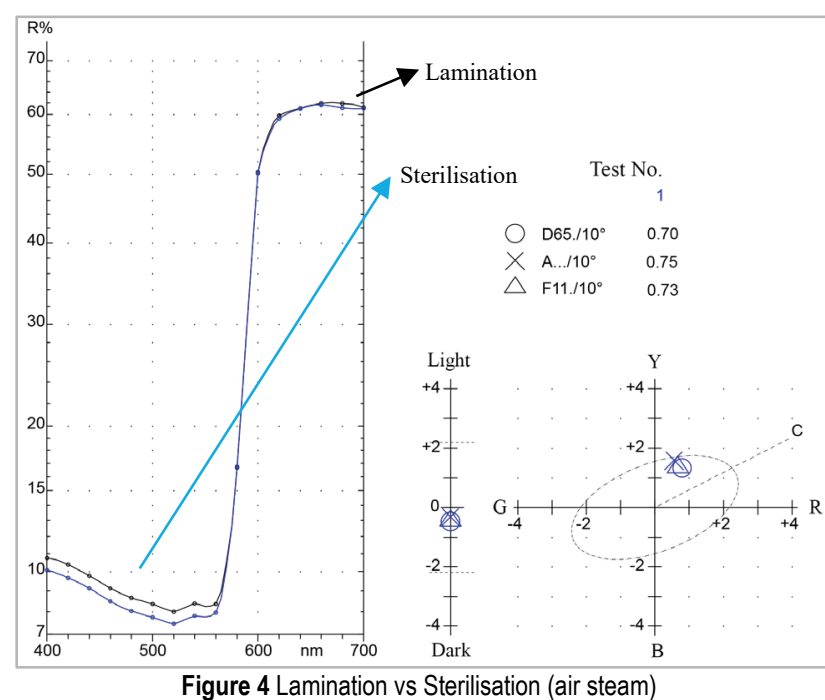

The most significant and unacceptable deviation occurs after the lamination process. By laminating the transparent polyester layer (PET) onto the aluminium surface, a change occurs in all parts of the CIE L ${ }^{*} a^{*} b^{*}$ color system. The problem that arises when the transparent polyester is laminated onto the aluminium surface is inconsistent graphic reproduction, which could be prevented by adjustments to the color recipe. The greatest problem with the printing of food packaging which use multiple types of packing materials is to unify the CIE $\mathrm{L}^{*} \mathrm{a}^{*} \mathrm{~b}^{*}$ color values. It is impossible to achieve identical values on multi-layered flexible packaging that contains aluminium and packaging that consists solely of transparent polymeric materials. An identical imprint would suggest a different input color recipe, depending on the substrate, and this is not a realistic expectation for a printing machine. Because of all the specificities of each packaging material, it is necessary to define the maximum tolerance range, define the standard color on each substrate and then measure the same. When measuring and evaluating samples, a relatively large deviation in Podravka Red after mounting $(\Delta E=3.80)$ was less noticeable than the smaller deviations in other colors.

\section{CONCLUSION}

In order that desired quality of the finished product can be guaranteed it is crucial that all input parameters are definied (printing technique, material specification, number of colors, separation and permitted color deviation, etc). The graphic preparation, printing and lamination processes as well as final processing of finished products will provide high-quality results if the criteria and tolerance ranges are set for every process stage. Measuring as a part of standardised process enables monitoring of deviations thus resulting in packaging produced within acceptable color tolerance ranges, and generally invisible to most consumers' eyes. Standardisation and monitoring of all stages of such a process is the only way packaging can be produced within the defined area of tolerated color deviation.

Many criteria influence the assessment of packaging quality and consumers are highly demanding so any flaws in packaging open the way up for the competition. Aside from its primary functions, product storage and 
functionality, a string of high-level requirements and criteria has been set to packaging of today. Apart from design and visual harmony for packaging and color recognition associated with a brand, the consumer must be essentially at ease with handling, opening, manipulating and re-closing a product. The interaction and the 'story behind the packaging' are important, as is its sustainable development and environmental care. In order that an initial impression is made of the packaging's attractiveness on the shelf so that the average consumer's attention may be retained for a few seconds, a multi-disciplinary approach and great complexity in its performance is required.

The aim of this paper was to determine the extent to which spot color deviation occurred on packaging during the finished product's printing, finishing and processing (sterilisation) stages. The Podravka Red color was measured following the aforementioned stages and compared to the stated standard with the aim of achieving better qualitative properties for the finished product and its appearance on the shelf. Based on the measurements, the stages that influenced color deviations most, were determined. The initial measurement point was the formula for the Podravka Red and the allowed tolerance range $(\Delta E \leq 2)$.

Measurement results for Podravka Red color were obtained. The sterilisation process caused deviation in CIEL ${ }^{*} \mathrm{a}^{*} \mathrm{~b}^{*}$ spot color values. Measurements showed that deviations in spot colors during the finishing stages were not significant and that the greatest deviation occurred during the lamination stage. Implemented processes (print, lamination and sterilisation) also caused changes to process colors (blue-green, purple, yellow and black), i.e. the colors of food that appear on the design. Changes to the process color were not the subject of this Research, but the Company Anilox measured the applied color atlas so that it could be used in any future research.

This paper has:

- Defined spot color value deviations of CIEL ${ }^{*} a^{*} b^{*}$ color space for each individual phase of the graphic and technological process and the final food product processing stage,

- Proposed guidelines to achieve deviations within the previously defined tolerance ranges for individual colors, and

- Determined those parts of the technological process that have the greatest effect on color deviations.

The process of creating packaging, from inception to realisation, is long, complex and unpredictable. Each project poses new challenges, each stage requires further adjustments, and a multi-disciplinary approach is required from different teams in order to place a product on the market in a timely manner. Today the shop shelf is like a jungle: overgrown, densely saturated and 'attacking' consumers from all angles. It is difficult to determine the most important packaging property for the customer: is he/she consciously guided by his/her decision about the purchase or is his/her decision based on an emotional connection with a recognised brand. The most difficult of all is achieving uniformity of the protected spot color on different packaging materials using different techniques and suppliers. Printing on a mono material with a white background is a huge difference from printing on e.g. a multi-layered flexible material with aluminium or metallised foil. Each of the afore-mentioned parameters affects the measured colors value, the definition of tolerance areas and acceptable values. Unfortunately, the Podravka Red, as with other well-known brands, cannot achieve a color that will always be within the desired tolerance area. Standardisation can be defined with one supplier, one type of packaging material, one type of printing ink, identical lamination agent or printed forms made under the same conditions, but all of the above still cannot guarantee absence of undesired deviations, although they will most certainly be reduced to a minimum. No global food company uses a single manufacturer of printing forms or a print shop, but instead will use the services provided by a few of them. Implementing standardisation is a real challenge and the unattainable 'Holy Grail' for every company. The procedures stated in this paper show how such limitations can be kept under control and provide guidelines for a proper approach to the packaging manufacturing process.

On the basis of this paper it is possible to continue further research into the field of process color deviations of other packaging materials, other printing and finishing techniques and other processing procedures for finished food products.

\section{REFERENCES}

[1] Kotler, P. \& Armstrong, G. (2012). Principles of Marketing. $14^{\text {th }}$ edition, Upper Saddle River, New Jersey: Prentice Hall.

[2] Fenko, A., Schifferstein, H. N. J., \& Hekkert, P. (2010). Shifts in sensory dominance between various stages of user - product interactions. Applied Ergonomics, 41(1), 34-40. https://doi.org/ 10.1016/j.apergo.2009.03.007

[3] Robertson, G. L. (2013). Food Packaging Principles and Practice. Boca Raton, Florida: Taylor \& Francis Group.

[4] Vujković, I., Galić, K., \& Vereš, M. (2007). Ambalaža za pakiranje namirnica. Zagreb, Hrvatska: Tectus.

[5] Vujković, I. A. (1997). Polimerna i kombinovana ambalaža. Novi Sad, Srbija: Poli.

[6] Galić, K. (2006). Marking and Application of Plastics for Food Packaging. Ambalaža, 11, 15-17.

[7] Hanlon, J. F., Kelsey, R. J., \& Forcinio, H. E. (1998). Handbook of Package Engineering. Boca Raton, Florida: Taylor \& Francis Group.

[8] The Future of Packaging: Long Term Strategic Forecasts to 2028, Smithers Pira. (2018, October $\left.5^{\text {th }}\right)$. Retrieved from https://www.smitherspira.com/industry-marketreports/packaging/packaging-long-term-strategic-forecaststo-2028

[9] Rebollar, R., Lidón, I., Serrano, A., Martín, J., \& Fernández, M. J. (2011). Influence of chewing gum packaging design on consumer expectation and willingness to buy. An analysis of functional, sensory and experience attributes. Food Quality and Preference, 24, 162-170. https://doi:10.1016/j.foodqual.2011.10.011

[10] Itten, J. (2004). The Art of Color. New York, NY: John Wiley \& Sons.

[11] Tomerlin, R. (2009). Utjecaj korporativnog identiteta na ugled društveno odgovorne tvrtke. Magistarski rad, Grafički fakultet, Zagreb.

[12] Niederstadt, D. (2016). Staying ahead of trends in flexible packaging. Retrived from https://flexo-gravure.com/ dossiers/staying-ahead-of-trends-in-flexible-packaging/

[13] Bolanča, S. (2013). Tisak ambalaže. Zagreb, Hrvatska: Sveučilišna naklada. 
[14] Valdec, D., Miljković, P., \& Auguštin, B. (2017). The influence of printing substrate properties on color characterization in flexography according to the ISO specifications, Tehnički glasnik, 11(3), 73-77.

[15] Anyadike, N. (2003). Introduction to Flexible Packaging. Surrey, UK: Pira International Ltd.

[16] Thermal Processing of Food. (2014). Retrieved from http://safefood360.com/resources/Thermal-Processing-ofFood.pdf

[17] Kuehni, R. G. (2003). Color space and its divisions: color order from antiquity to the present. New Jersey: John Wiley \& Sons. https://doi.org/10.1002/0471432261

[18] Clark, F. J. J., McDonald, R., \& Rigg, B. (1984). Modifications to the JPC79 Colour-Difference Formula. Journal of the Society of Dyers and Colourists, 100, 128132. https://doi.org/10.1111/j.1478-4408.1984.tb00969.x

[19] Schläpfer, K. (1994). Color Gamut Compression Correlations between Calculated and Measured Values. IFRA Project Report, EMPA.

\section{Contact information:}

Renata TOMERLIN, MSc.

Podravka d. d. (plc),

Ante Starčevića 32,

48000 Koprivnica, Croatia

E-mail: renata.tomerlin@podravka.hr

Mario TOMIŠA, PhD, Assoc. Prof.

University North,

Trg dr. Žarka Dolinara 1,

48000 Koprivnica, Croatia

E-mail: mario.tomisa@unin.hr

Damir VUSIĆ, PhD, Assoc. Prof

University North,

Jurja Križanića 31b,

42000 Varaždin, Croatia

E-mail: damir.vusic@unin.hr 